\title{
Simulation of wheat ontogenesis. III. Effect of variety, nitrogen fertilization and water stress on leaf appearance and final leaf number in the field
}

\author{
F. Miglietta \\ I.A.T.A.-CNR, Institute of Environmental Analysis and Remote Sensing for Agriculture, P.le delle Cascine, 18, I-50144 Florence, \\ Italy
}

\begin{abstract}
In the first 2 parts of this study, rate of leaf appearance was supposed to be a function only of temperature and not of variety. Effects of nitrogen fertilization and water shortage on both leaf appearance and final leaf number were not considered. In this third paper results of published field experiments conducted in North America and of original experiments conducted in Italy were collected in order to study leaf appearance rates of different varieties and to analyse the effect of nitrogen fertilization and water stress. Data analysis showed that leaf appearance, final leaf number and phasic development of wheat are independent of all these factors. Finally, simulation accuracy of the model was validated by comparing field observations and calculations.
\end{abstract}

\section{INTRODUCTION}

A model for calculating the rate of appearance of subsequent main stem leaves and for predicting phasic development of wheat was presented in 2 previous studies (Miglietta 1991a, b). The model assumes that both initiation and appearance rates of main stem leaves are functions of temperature and independent of daylength (Miglietta 1989), and that the time between initiation and appearance of a leaf increases linearly with leaf number (Miglietta 1991a). Phasic development of wheat is described in terms of the number of emerged leaves. The final number of leaves depends on the photoperiodic response of the variety and on flower synchronisation, which in turn also depends on temperature and vernalization (Miglietta 1991b). The photoperiodic response of spring wheats and fully vernalized winter wheats is described by an exponential decrease in the final number of main stem leaves, with increasing daylength, to a minimum of 6 leaves.

The model was validated by means of a comparison with both original and published field experiment data, and its performance was excellent for a wide range of environmental conditions. In the model, differences among varieties were only considered in terms of different responses in the final number of leaves to daylength. The effect of variety on the rate of leaf initiation and appearance was considered to be negli- gible. This was concluded on the basis of an analysis of experiments under controlled conditions, but it was only verified for 2 varieties in a single field experiment. The effects of nitrogen fertilization and water stress on the rate of leaf initiation and appearance, on final leaf number and on phasic development of wheat were not considered in the model.

In the present study, results of published field experiments and of a series of original field experiments are considered in order to study leaf appearance rates of different varieties and to analyse the effect of nitrogen fertilization and water stress on both leaf appearance and final leaf number. Published data come from a large-scale collaborative experiment in North America. Original experiments were conducted in Italy, in a joint research project involving different institutions and experimental farms.

Simulation accuracy of the model is tested in this study by means of a comparison between observed and calculated values of the final main stem leaf number, the date of heading, and the appearance of main stem leaves over time.

\section{MATERIALS AND METHODS}

Field experiments in USA and Canada. A comparative study, 'Agricultural Microclimatological Measurements for Comparing Production Functions and Water 
Use Efficiency', was sponsored from 1984 to 1986 by the US National Science Foundation, Agriculture Canada and the Agricultural Research Service of the US Dept of Agriculture. The response of selected wheat cultivars to climate and to water and nitrogen applications was studied simultaneously at 5 sites in North America. A common experimental design was employed, and the same instruments and techniques were used to take measurements of microclimate and plant growth conditions (Reginato et al. 1988). Phenological observations were made at each site, but complete data sets are available only for Manhattan, Kansas $\left(39^{\circ} 09^{\prime} \mathrm{N}, 96^{\circ} 37^{\prime} \mathrm{W}\right)$, and Mandan, North Dakota ( $46^{\circ} 46^{\prime} \mathrm{N}, 100^{\circ} 55^{\prime} \mathrm{W}$ ) (Bauer et al. 1988).

Wheat development was determined weekly from emergence onwards by the Haun and the ZadoksChang-Konzak scales (Bauer et al. 1983) on 2 different varieties (V1 and V2). These were the cultivars 'Colt' and 'Brule' in Manhattan, Kansas, and 'Colt' and 'Nordstar' in Mandan, North Dakota. The variety Colt was grown at each site for easy comparison of the effect of climate on development (Bauer et al. 1988). Other variables in the experiments considered here are soil water level ( $W 1=$ dry-Iand or rain-fed conditions; W3 $=$ well-watered condition) and nitrogen fertilization $\left(\mathrm{N} 1=50\right.$ to $60 \mathrm{~kg} \mathrm{NO}_{3}{ }^{-}-\mathrm{N} \mathrm{ha}^{-1} ; \mathrm{N} 3=160 \mathrm{~kg} \mathrm{NO}_{3}{ }^{-}-\mathrm{N}$ $\left.\mathrm{ha}^{-1}\right)$. Details of experimental design and water and nitrogen treatments are given by Reginato et al. (1988).

Field experiments in Italy. Three field trials were performed in the 1988-89 winter season in a joint research project established by 2 research institutes (CeSIA and IATA, Florence) and 2 agricultural extension institutions (CERAS and ERSA, Emilia-Romagna, Bologna). Three Italian winter wheat varieties with marked differences in earliness of maturity ('Pandas', early; 'Centauro', medium; 'Salmone', late) were grown in the 1988-89 season under 2 fertilization treatments at 3 experimental farms located in EmiliaRomagna (Martorano 5, Ostellato and Stuard). Plots of $65 \mathrm{~m}^{2}$ were sown, with rows $10 \mathrm{~cm}$ apart, on the same date (31 October) at each location; each plot was replicated twice. In the first fertilization treatment no nitrogen was applied to the plots, and in the second, 140 to $160 \mathrm{~kg} \mathrm{~N} \mathrm{ha}{ }^{-1}$, in the form of $\mathrm{NO}_{3}{ }^{-}$, were applied on 2 dates (31 October and $20 \mathrm{March}$ ). The same amounts of phosphorus $\left(120 \mathrm{~kg} \mathrm{ha}^{-1}\right)$ and potassium $\left(60 \mathrm{~kg} \mathrm{ha}^{-1}\right)$ were applied to each plot. Data for the cultivar Salmone in the Ostellato experiment are not considered, due to the failure of the crop to emerge; in the Stuard experiment, the variety Centauro was replaced by a variety having comparable earliness ('Costantino').

Weather data were recorded daily throughout the growing season at automatic weather stations (ERSA) located close to the experimental fields.

Haun stage measurements and counts of final main stem leaf number were performed on each plot. Phenological stages of development were recorded using the Zadoks scale.

\section{RESULTS AND DISCUSSION}

\section{Eifect of variety}

The simulation model discussed in this series of papers assumes that the difference in rate of leaf appearance among varieties is generally small, and thus that it can be neglected (Miglietta 1989, Miglietta 1991a). This assumption was based upon observations made in several laboratory experiments, in which the total number of leaf primordia formed by the wheat plant and the time taken by the plant from emergence to the double ridge stage were measured (Holmes 1972, Levy \& Peterson 1972, Allison \& Daynard 1976, Rahman \& Wilson 1977, Pirasteh \& Welsh 1980). In these experi-
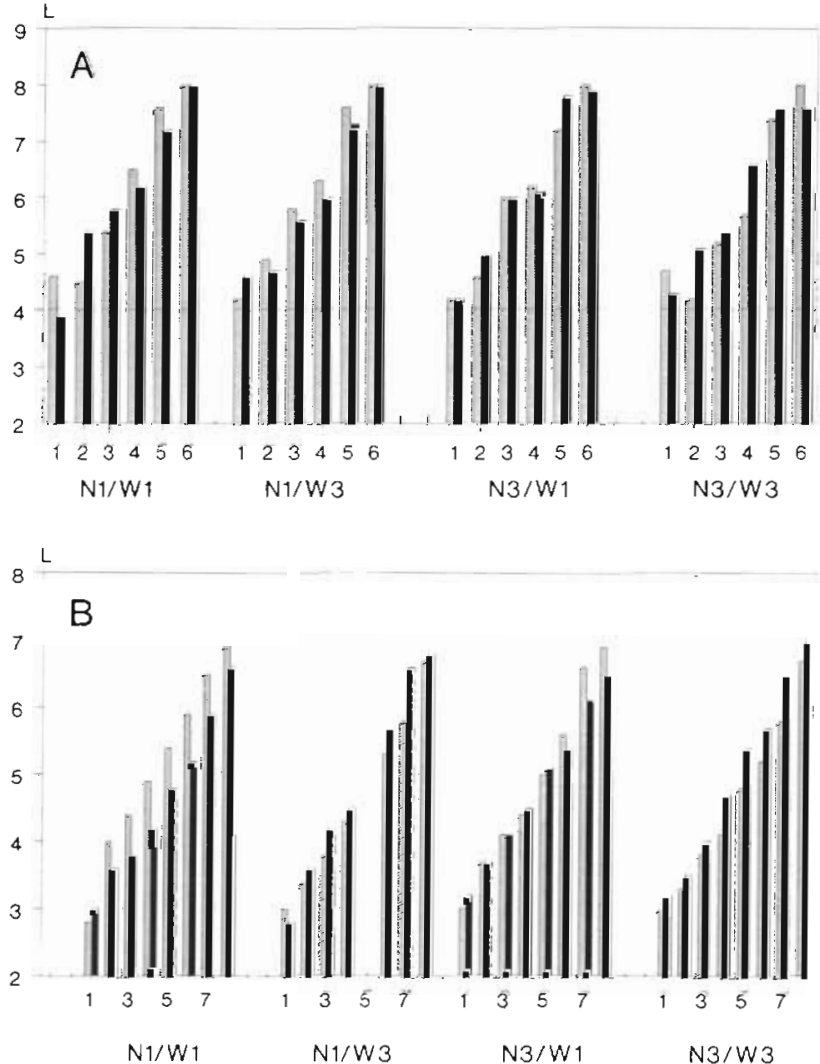

Fig. 1. Number of main stem leaves emerged (L) at each weekly sampling date (numbers on horizontal axis indicate subsequent samples) in each one of the 4 nitrogen/irrigation treatments (see 'Materials and methods') at (A) Manhattan. Kansas, and (B) Mandan, North Dakota, LSA. Observations are shown for the variety 'Colt' (filled bars) and for the varieties 'Brule' (Manhattan) and 'Norstar' (Mandan) (hatched bars) 
ments the calculated rate of leaf primordia initiation was observed to be almost the same for the different varieties tested, and it was inferred that the rate of leaf appearance was also likely to be independent of variety This conclusion was confirmed by comparing leaf appearance rates recorded for 2 varieties of different origin in a field experiment (Miglietta 1991a), but it was not validated further.

Data obtained in the field experiments in the USA and in Italy are here used to evaluate the effect of different varieties on leaf appearance rate. Haun stage measurements from emergence to heading, made in the field, and the calculated rates of leaf appearance were compared and statistically analysed. Results of this comparison are given in Fig. $1 \mathrm{~A}$ for the experiment conducted in Manhattan and in Fig. 1B for the experiment conducted at Mandan; for each nitrogen and water treatment, the number of leaves appearing on the main stem in subsequent samplings is plotted. Differences in the number of leaves formed by the 2 varieties at successive observation dates appear to be very small for all the treatments considered. The effect of variety on rate of leaf appearance was tested by multifactor variance analysis (Tables 1 \& 2) and was found to be not significant.

Data for the 3 varieties grown in the experiments in Italy are compared separately for each experiment and for each nitrogen treatment. Haun stage measurements taken in the plots with no nitrogen fertilization are presented in Fig. 2 for the experiments performed at Martorano 5, Stuard and Ostellato farms; measurements taken on fertilized plots are given in Fig. 3. Results of multifactor variance analysis are reported in Table 3.

Data in Figs. 2 \& 3 clearly show that the differences in number of leaves between varieties were negligible, irrespective of sampling date. The results of multifactor variance analysis in Table 3 indicate that variety had no effect upon rate of leaf appearance.

These results are in contrast with those of a field experiment reported by Syme (1974), in which rate of leaf appearance was found to be slightly different for different varieties. In that experiment, a split-plot design with 4 dates of sowing and 2 replications was adopted, and 2 plants per plot were tagged in order to record leaf appearance. Data from the 4 sowings were then pooled and the mean rate of leaf appearance was calculated, for each variety, as the slope of the line fitted between the number of main stem leaves which had appeared and the number of days from sowing. However, since the rate of leaf appearance decreases for every subsequent leaf (Miglietta 1991a) and varieties may have different final leaf numbers, the variety with the largest final leaf number will on average

Table 1. Multifactor variance analysis of leaf appearance rates recorded in Manhattan, Kansas, USA, in the 1984-85 season. The effect of observation date is always significant because it is dependent upon the different thermal conditions occurring between 2 subsequent observations

\begin{tabular}{|lcccc|}
\hline Source of variation & Sum of squares & df & Mean square & F-ratio \\
\hline Variety & 0.0000864 & 1 & 0.0000864 & $0.002^{\mathrm{ns}}$ \\
Fertilization & 0.0902358 & 1 & 0.0902358 & $2.560^{\mathrm{ns}}$ \\
Irrigation & 0.0619635 & 1 & 0.0619635 & $1.758^{\mathrm{ns}}$ \\
Observation date & 0.5718128 & 6 & 0.0953021 & $2.704^{\cdot}$ \\
Residual & 1.6212285 & 46 & 0.0352441 & \\
Total (corr.) & 2.3453270 & 55 & & \\
ns & & & \\
\hline
\end{tabular}

Table 2. Multifactor variance analysis of leaf appearance rates recorded in Mandan, North Dakota, USA in the $1985-86$ season The effect of observation date is always highly significant because it is dependent upon the different thermal conditions occurring between 2 subsequent observations

\begin{tabular}{|lcccc|}
\hline Source of variation & Sum of squares & df & Mean square & F-ratio \\
\hline Variety & 0.0003710 & 1 & 0.0003710 & $0.167^{\mathrm{ns}}$ \\
Fertilization & 0.0000284 & 1 & 0.0000284 & $0.013^{\mathrm{ns}}$ \\
Irrigation & 0.0001854 & 1 & 0.0001854 & $0.083^{\mathrm{ns}}$ \\
Observation date & 0.0812282 & 4 & 0.0203070 & $9.129 \cdots$ \\
Residual & 0.0711797 & 32 & 0.0022244 & \\
Total (corr.) & 0.1529928 & 39 & & \\
ns. & & & \\
Not significant; $\cdots$ significant at $\mathrm{p}=0.01$ & & \\
\hline
\end{tabular}



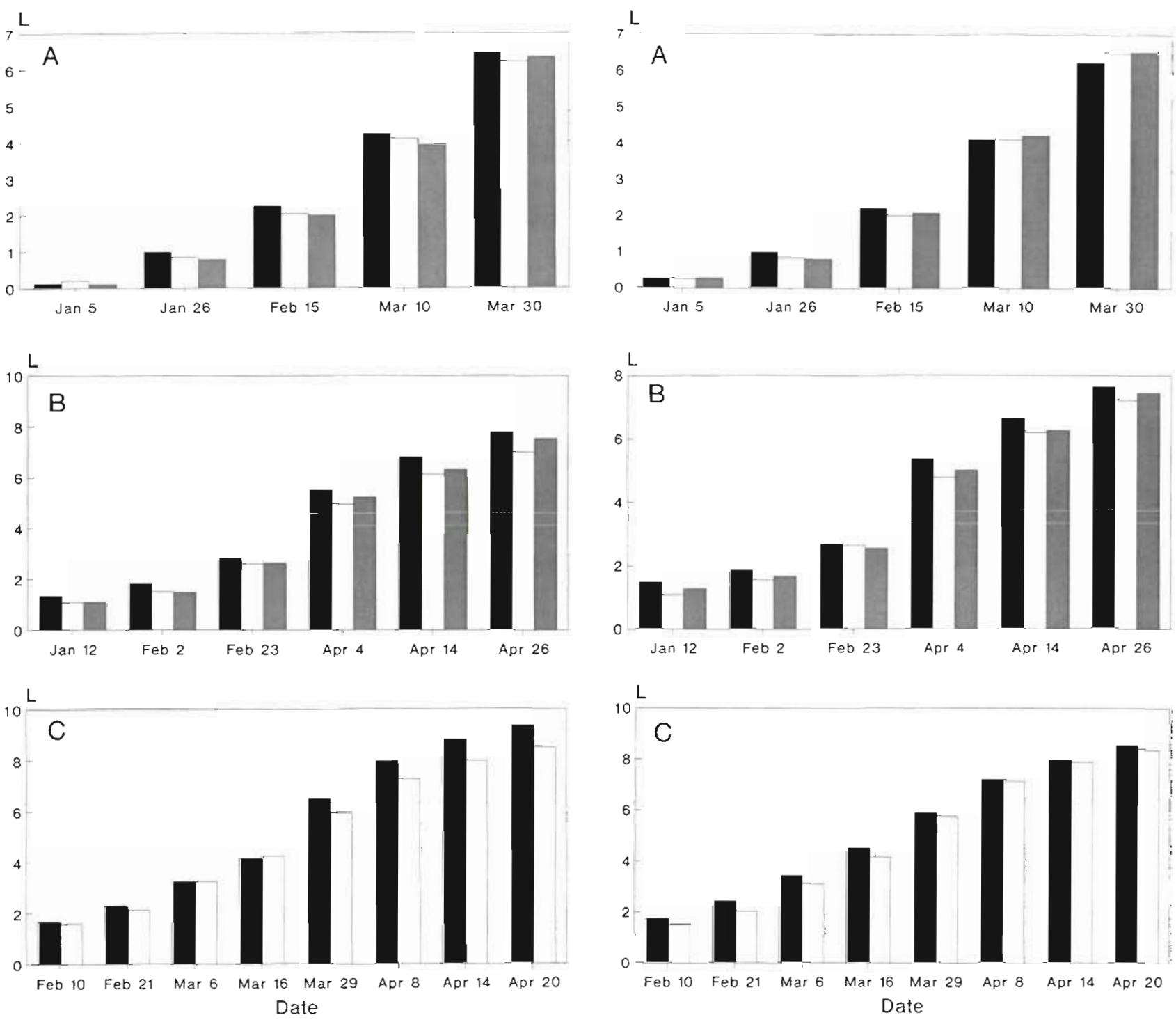

Fig. 2. Number of main stem leaves emerged (L) at each sampling date (1989) in non-fertilized experimental plots at (A) Martorano 5, (B) Stuard and (C) Ostellato farms in Italy. Filled bars: cultivar 'Pandas'; open bars: cultivar 'Centauro' or 'Costantino'; hatched bars: cultivar 'Salmone

exhibit the slowest rate of leaf appearance. Hence, the calculation procedure adopted by Syme (1974) does not provide full evidence that the rate of leaf appearance is different for different varieties.

\section{Effect of nitrogen fertilization}

Based upon the observation that crops grown with high nitrogen supply stay green longer than crops grown with low nitrogen supply, it is often concluded that a high supply of nitrogen retards wheat development. However, more careful laboratory observations

Fig. 3. Number of main stem leaves emerged (L) at each sampling date (1989) in experimental plots fertilized with nitrogen, at (A) Martorano 5, (B) Stuard and (C) Ostellato farms in Italy. Filled bars: cultivar 'Pandas'; open bars: cultivar 'Centauro' or 'Costantino'; hatched bars: cultivar 'Salmone'

have shown that nitrogen treatments may have a positive effect on the number of spikelets and kernels per ear but do not affect the duration of the vegetative phase (Masle-Meynard \& Sebillotte 1981, Frank \& Bauer 1982, Davidson \& Campbell 1983).

Numbers of leaves at low and high nitrogen supplies are given in Fig. 4 for the Manhattan and Mandan experiments; these data represent averages across varieties, since leaf appearance rates are independent of variety. The results confirm that leaf appearance rates were not affected by the level of nitrogen fertilization. It is worth noting that the effect of nitrogen fertilization on final yield was substantial in the 2 experiments 
Table 3. Variance analysis of leaf appearance rates measured in the field at 3 farms in Italy. The effect of observation date is always highly significant because it is dependent upon the different thermal conditions occurring between 2 subsequent observations

\begin{tabular}{|c|c|c|c|c|}
\hline Source of variation & Sum of squares & $d f$ & Mean square & $F$-ratio \\
\hline \multicolumn{5}{|l|}{ Martorano 5} \\
\hline Variety & 0.0002132 & 2 & 0.0001066 & $1.237^{\mathrm{ns}}$ \\
\hline Fertilization & 0.0000269 & 1 & 0.0000269 & $0.312^{\text {ns }}$ \\
\hline Observation date & 0.6190572 & 4 & 0.1547643 & $1000^{\cdots}$ \\
\hline Residual & 0.0403174 & 468 & $8.61482 \times 10^{-5}$ & \\
\hline Total (corr.) & 0.6604542 & 475 & & \\
\hline \multicolumn{5}{|l|}{ Ostellato } \\
\hline Variety & 0.0001950 & 1 & 0.0001950 & $0.598^{\mathrm{ns}}$ \\
\hline Fertilization & 0.0000294 & 1 & 0.0000294 & $0.090^{\mathrm{ns}}$ \\
\hline Observation date & 1.4884941 & 8 & 0.1860618 & $570.87 \cdots$ \\
\hline Residual & 0.1104873 & 339 & $3.25921 \times 10^{-4}$ & \\
\hline Total (corr.) & 1.5996196 & 349 & & \\
\hline \multicolumn{5}{|l|}{ Stuard } \\
\hline Variety & 0.0004976 & 2 & 0.0002488 & $0.740^{\mathrm{ns}}$ \\
\hline Fertilization & 0.0002563 & 1 & 0.0002563 & $0.762^{\mathrm{ns}}$ \\
\hline Observation date & 0.7885398 & 5 & 0.1577080 & $469.081^{\cdots}$ \\
\hline Residual & 0.2380338 & 708 & $3.36206 \times 10^{-4}$ & \\
\hline Total (corr.) & 1.0273895 & 716 & & \\
\hline
\end{tabular}
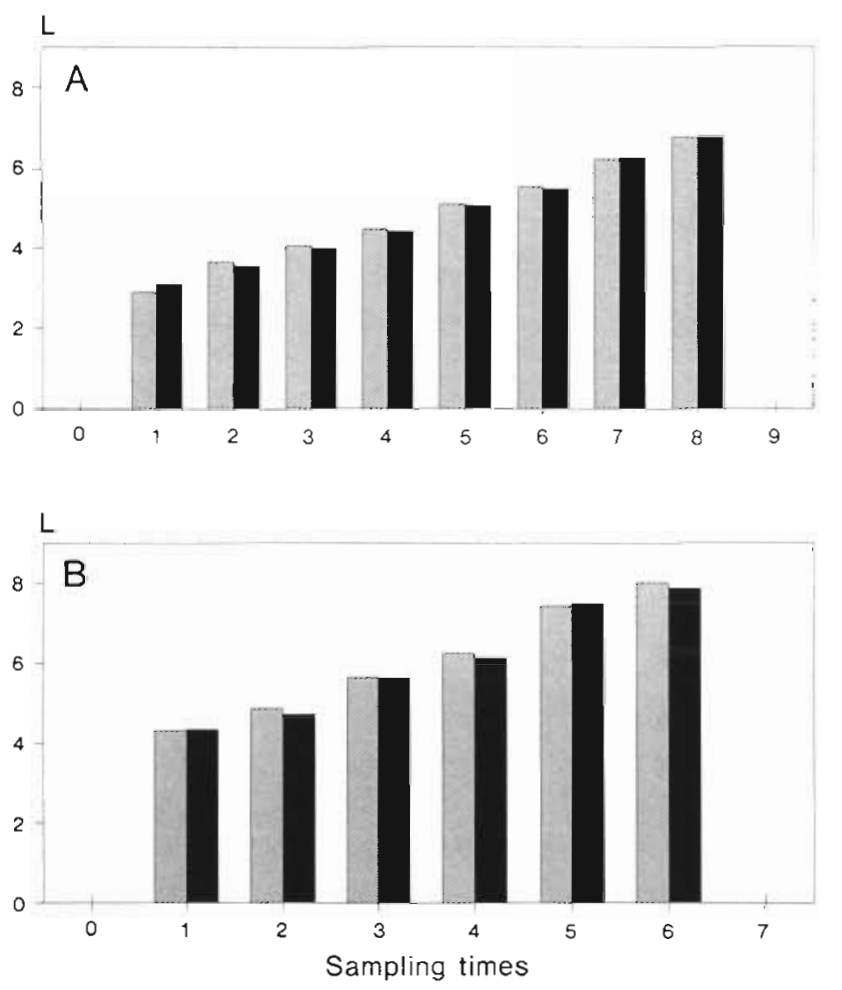

Fig. 4. Number of main stem leaves emerged (L) at each weekly sampling date (number on horizontal axis indicate subsequent samples) in plots with high nitrogen (solid bars) and low nitrogen (hatched bars) fertilization, at (A) Manhattan, Kansas, and (B) Mandan, North Dakota, USA
Yields in the N1 and N3 treatment plots were respectively $2.585 \mathrm{t} \mathrm{ha}^{-1}$ and $2.707 \mathrm{tha}^{-1}$ of wheat grains in Manhattan, and $1.832 \mathrm{tha}^{-1}$ and $3.162 \mathrm{t} \mathrm{ha}^{-1}$ in Mandan (Major et al. 1988a). Results obtained in the experiments in Italy are given in Fig. 5 for the Martorano 5 , Ostellato and Stuard farms. Here, an average difference of 8 to $10 \%$ in final grain yield was obtained by nitrogen fertilization.

Data from all the experiments clearly indicate that nitrogen fertilization had no significant effect upon the rate of leaf appearance. This is also confirmed by the results of multifactor variance analysis (Tables $1,2 \& 3$ ). The timing of developmental phases and the final leaf number were also unaffected, as they were the same for both nitrogen treatments.

\section{Effects of water shortage}

Gallagher et al. (1979) found that mild water stress led to a decrease in the rate of epidermal cell extension but had no effect upon the duration of the leaf extension process or upon the timing of phenological development. It is also well known that even moderate water stress can affect crop assimilation rate and thus the final yield.

Crops sown at Manhattan and in Italy did not suffer from lack of water, but in Mandan irrigation strongly affected the growth rate and final yield of crops grown 

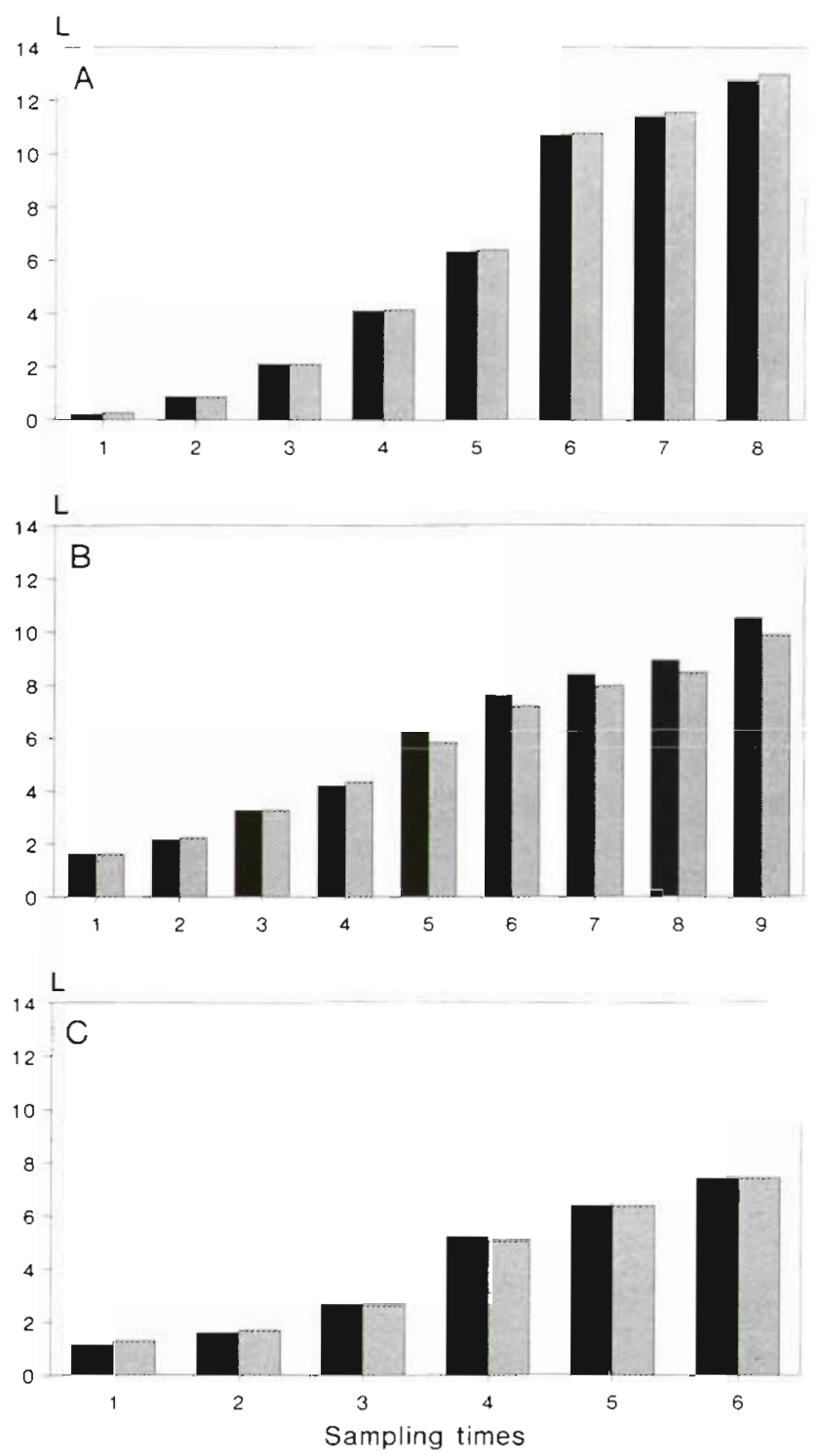

Fig. 5. Number of main stem leaves emerged ( $L$ ) at each weekly sampling date (numbers on horizontal axis indicate subsequent samples) in plots with high nitrogen (solid bars) and low nitrogen (hatched bars) fertilization, at (A) Martorano 5. (B) Stuard and (C) Ostellato farms in Italy

with both low (N1) and high (N3) nitrogen fertilization. In the $\mathrm{N} 1$ treatment the grain yield was $1.074 \mathrm{tha}^{-1}$ for rain-fed conditions and $1.161 \mathrm{t} \mathrm{ha}^{-1}$ for well-watered plots. In the N3 treatment yields ranged from 2.064 to $3.092 \mathrm{tha}^{-1}$ The mean growth rate of irrigated plots was $17.36 \mathrm{~g} \mathrm{~m}^{-2} \mathrm{~d}^{-1}$, whereas that of non-irrigated ones declined to $8.49 \mathrm{~g} \mathrm{~m}^{-2} \mathrm{~d}^{-1}$ (Major et al. 1988a, b). Nevertheless, the rate of leaf appearance appears to have been unaffected by the irrigation treatments, as is clearly shown in Fig. 6 and statistically confirmed by the results of the variance analysis given in Table 2 . In addition, the date of heading as well as the final leaf number were unaffected by the irrigation treatments,

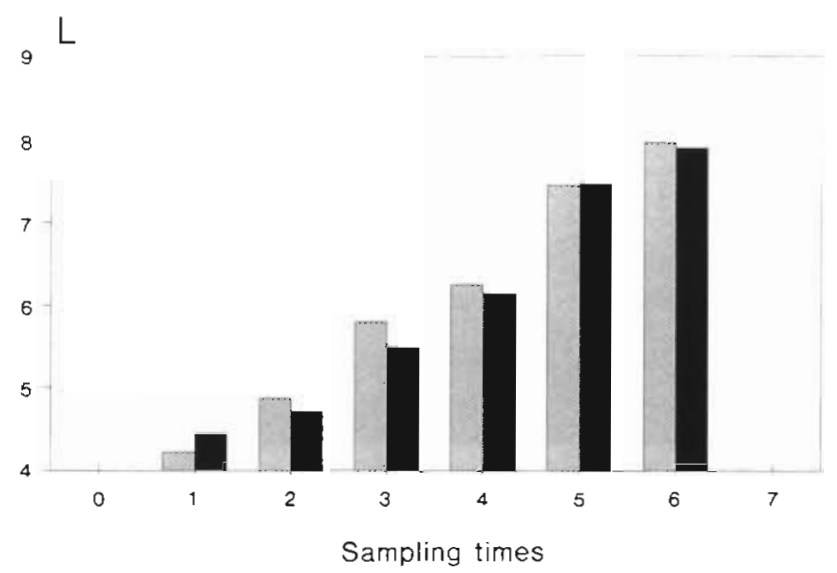

Fig. 6. Mean number of main stem leaves emerged (L) at each weekly sampling date (numbers on horizontal axis indicate subsequent samples), in well-watered (solid bars) and nonirrigated (hatched bars) plots of the 2 varieties tested at Mandan, North Dakota, USA, in the 1988-89 season

as they remained the same for both treatments. It may be concluded that both wheat development and the leaf appearance process are independent of one of the major limiting factors for biomass growth and yield.

\section{Simulation accuracy}

The model under discussion makes it possible to predict the final leaf number of a crop sown on any date before the coldest period of the year, and to simulate the appearance of leaves on the main stem. The accuracy of predictions and simulations can be evaluated by comparing the models' performance with field data. For such purposes a model parameter representig varietal response to photoperiod has to be estimated first, and then model performance must be evaluated.

The model assumes that different wheat varieties can respond differently to photoperiod. This response is expressed by the relationship between daylength ( $d$; hours per day) on the date of crop emergence and the final number of leaves that are formed in the main stem. $\left(F_{1}\right)$, as follows (Miglietta 1991b):

$$
F_{1}=\sigma \exp (-0.25 d)+6.5
$$

where $\sigma$ is a coefficient characterizing the variety's sensivity to daylength. This coefficient can be estimated in laboratory experiments by counting the final number of leaves in vernalized or non-vernalizationrequiring plants that are grown under different daylengths, or, when laboratory data are not available, it can be estimated on the basis of the latitude for which any given variety has been artificially selected (Miglietta 1991b).

Moreover, estimates of $\sigma$ can be directly obtained on the basis of data from field experiments. In this case, the 
Table 4. Field experiments from which data were used to estimate photoperiodic sensitivity ( $\sigma$ ) of the wheat variety 'Colt'. Last column indicates the difference found between calculated and observed dates of heading

\begin{tabular}{|lccrr|}
\hline Experimental sites & Lat. (N) & Long. (W) & Season & Difference (d) \\
\hline Lethbridge (Canada) & $49^{\circ} 42^{\prime}$ & $112^{\circ} 50^{\prime}$ & $1984-85$ & -1 \\
& & & $1985-86$ & 1 \\
Sandhills (NB, USA) & $41^{\circ} 37^{\prime}$ & $100^{\circ} 50^{\prime}$ & $1984-85$ & 1 \\
Mandan (ND, USA) & & & $1985-86$ & 2 \\
Manhattan (KS, USA) & $46^{\circ} 46^{\prime}$ & $100^{\circ} 55^{\prime}$ & $1984-85$ & -3 \\
& $39^{\circ} 09^{\prime}$ & $96^{\circ} 37^{\prime}$ & $1985-86$ & 3 \\
\hline
\end{tabular}

model itself can be used to estimate the photoperiodic response of varieties. This can be done by running it iteratively and by changing, for each run, the photoperiodic response of the variety under study. This procedure aims to find the value of $\sigma$ that minimizes the difference between observed and calculated final leaf numbers or heading dates. The estimates of oobtained in this way for any given variety are more reliable whenever the range of latitudes and the number of years for which experimental observations are available are larger.

The variety Colt was grown in the experiments performed in the USA. No laboratory data are presently available for accurately estimating the photoperiodic response of this variety, and I do not know the latitude for which the variety was selected. The iterative procedure described above was therefore used in order to estimate $\sigma$. A list of the field experiments used in this procedure is given in Table 4 (Hubbard et al. 1988), together with the difference (in days) found between observed and calculated dates of heading. The value of $\sigma$ that minimized the difference between observed and calculated dates of heading for this variety was found to be 29.5 .

Laboratory data to estimate the photoperiodic response coefficient of the 4 varieties tested in the experiments in Italy are also not available. A rough evaluation of $o$ for these varieties is therefore possible on the basis of the latitude for which they were selected, but this method cannot take into account developmental differences resulting from different breeding programs developed at the same institute. In fact, the varieties Pandas, which develops faster, and Centauro, which develops slower, were both bred by the Società Produttori Sementi in Bologna. Hence, their photoperiodic response was again estimated on the basis of independent experimental data obtained in the field at several sites over several years (CERAS 1960-1989, Bindi et al. 1989). Iterative model runs were also used for the Italian varieties, according to the optimizing procedure described above, and estimated values of $\sigma$ were found to be $24.5 \pm 1.96$ for Pandas, $32.09 \pm 1.83$ for Centauro and Costantino and $40 \pm 1.71$ for Salmone. A list of the field experiments used in this procedure is given in Table 5, together with the difference (in days) found between observed and calculated dates of heading. Results of the experiments performed in the 1988-89 season are not included in the data set, thus keeping calibration and validation data independent of each other.

Model-based predictions of final leaf number and dates of heading in all the field experiments are given in Table 6. The model's simulation accuracy for leaf appearance is illustrated in Fig. 7 for the Manhattan and Mandan experiments, and in Fig. 8 for the experiments at Martorano 5, Ostellato and Stuard farms

The model overestimates final leaf number in the 2 experiments in the USA, which explains why simulated and observed numbers of leaves diverged in the last part of the growing season (Fig. 7). The date of heading was accurately calculated for both USA sites.

\section{CONCLUSIONS}

It has been demonstrated that, in the field, neither variety, nitrogen fertilization nor mild water stress affects leaf appearance, final number of main stem leaves, phasic development or timing of the different apical stages. This confirms my previous conclusion that wheat development is controlled mainly by temperature, photoperiod and vernalization; thus, the model presented in the first 2 parts of this study is widely applicable in the field

The model's accuracy was confirmed by comparing predicted and simulated data with field observations. The problems encountered in quantifying varietal response to photoperiod suggest that a rough evaluation of this response on the basis of the latitude for which a given variety was selected is not always feasible. However, the iterative procedure developed for such evaluation revealed that difficult and expensive daylength experiments in the laboratory are often unnecessary. This conclusion should encourage stronger efforts to collect and circulate the varietal and meteorological data recorded in the many variety trials conducted around the world.

Simulation models are useful tools in research and 
Table 5. Field experiments in Italy from which data were used to estimate photoperiodic sensitivity (o) of cultivars tested in the experiments conducted in Italy. Last 3 columns indicate the differences between observed dates of heading and those calculated using values of $\sigma$ equal to 40.0 for the variety 'Salmone', 245 for 'Pandas' and 32.09 for 'Centauro

\begin{tabular}{|c|c|c|c|c|c|c|}
\hline \multirow[t]{2}{*}{ Experimental sites } & \multirow[t]{2}{*}{ Lat. $(\mathrm{N})$} & \multirow[t]{2}{*}{ Long. (E) } & \multirow[t]{2}{*}{ Season } & \multicolumn{3}{|c|}{ Difference (d) } \\
\hline & & & & Salmone & Pandas & Centauro \\
\hline \multirow[t]{2}{*}{ Avanella (Firenze) } & $43^{\circ} 46^{\prime}$ & $11^{\circ} 23^{\prime}$ & $1981-82$ & -2 & & \\
\hline & & & $1982-83$ & -3 & & \\
\hline Basiliano (Udine) & $46^{\circ} 02^{\prime}$ & $13^{\circ} 05^{\circ}$ & $1984-85$ & 0 & 1 & 2 \\
\hline Nespoledo (Udine) & $46^{\circ} 01^{\prime}$ & $13^{\circ} 03^{\prime}$ & $1980-81$ & 2 & & \\
\hline Braccagni (Grosseto) & $42^{\circ} 53^{\prime}$ & $11^{\circ} 05^{\prime}$ & $1982-83$ & 2 & & \\
\hline \multirow[t]{2}{*}{ Torviscosa (Udine) } & $45^{\circ} 47^{\prime}$ & $13^{\circ} 20^{\prime}$ & $1981-82$ & 2 & & \\
\hline & & & $1984-85$ & -4 & 0 & -1 \\
\hline \multirow[t]{3}{*}{ Cremona } & $45^{\circ} 08^{\prime}$ & $10^{\circ} 01^{\prime}$ & $1982-83$ & -1 & & \\
\hline & & & $1983-84$ & 3 & & \\
\hline & & & $1984-85$ & 2 & 5 & 6 \\
\hline \multirow[t]{3}{*}{ Caorle (Venezia) } & $45^{\circ} 39^{\prime}$ & $12^{\circ} 50^{\prime}$ & $1982-83$ & 3 & & \\
\hline & & & $1983-84$ & 6 & & \\
\hline & & & $1984-85$ & -1 & 1 & 2 \\
\hline Catania & $37^{\circ} 30^{\prime}$ & $15^{\circ} 06^{\prime}$ & $1984-85$ & -7 & -10 & -10 \\
\hline \multirow[t]{3}{*}{ Fano (Pesaro) } & $43=51$ & $13^{\circ} 03^{\prime}$ & $1982-83$ & -2 & & \\
\hline & & & $1984-85$ & -1 & 0 & 0 \\
\hline & & & $1985-86$ & 0 & 1 & -1 \\
\hline Fontarronco (Arezzo) & $43^{\circ} 37^{\prime}$ & $11^{\circ} 50^{\prime}$ & $1982-83$ & -1 & & \\
\hline Ponte Galeria (Roma) & $41^{\circ} 52^{\prime}$ & $12^{\circ} 27^{\prime}$ & $1981-82$ & -1 & & \\
\hline Cavriglia (Arezzo) & $43^{\circ} 30^{\prime}$ & $11^{\circ} 31^{\prime}$ & $1981-82$ & 8 & & \\
\hline Cesa (Arezzo) & $43^{\circ} 21^{\prime}$ & $11^{\circ} 46^{\prime}$ & $1982-83$ & 3 & & \\
\hline \multirow[t]{3}{*}{ S. Angelo Lod. (Milano) } & $45^{\circ} 15^{\prime}$ & $9^{\circ} 25^{\prime}$ & $1981-82$ & -2 & & \\
\hline & & & $1982-83$ & -2 & & \\
\hline & & & $1984-85$ & -2 & 5 & 6 \\
\hline \multirow[t]{4}{*}{ Ravenna } & $44^{\circ} 25^{\prime}$ & $11^{\circ} 35^{\prime}$ & $1981-82$ & 5 & 0 & 0 \\
\hline & & & $1982-83$ & -3 & 1 & -1 \\
\hline & & & $1983-84$ & & 0 & 1 \\
\hline & & & $1984-85$ & -6 & -2 & -1 \\
\hline \multirow[t]{3}{*}{ Cadriano (Bologna) } & $44^{\circ} 30^{\prime}$ & $11^{\circ} 10^{\prime}$ & $1981-82$ & -1 & -2 & -5 \\
\hline & & & $1982-83$ & -4 & 0 & 2 \\
\hline & & & $1983-84$ & & 0 & 0 \\
\hline
\end{tabular}

Table 6. Calculated and observed dates of heading, predicted and observed final leaf number, for the different fertilization/ irrigation treatments in all the experiments

\begin{tabular}{|c|c|c|c|c|c|}
\hline \multirow[t]{2}{*}{ Site } & \multirow[t]{2}{*}{ Variety } & \multicolumn{2}{|c|}{ Date of heading } & \multicolumn{2}{|c|}{ Final leaf number } \\
\hline & & Observed & Predicted & Observed & Predicted \\
\hline Manhattan (KS, USA) & Colt & $3 \mathrm{May}$ & 3 May & 7 & 9.5 \\
\hline Mandan (ND, USA) & Colt & $8 \mathrm{Jun}$ & 7 Jun & 8 & 9 \\
\hline \multirow[t]{3}{*}{ Martorano 5 (Italy) } & Pandas & $27 \mathrm{Apr}$ & $25 \mathrm{Apr}$ & 10 & 9.8 \\
\hline & Centauro & 1 May & $30 \mathrm{Apr}$ & 10 & 10.3 \\
\hline & Salmone & $5 \mathrm{May}$ & $4 \mathrm{Mlay}$ & 11 & 11 \\
\hline \multirow[t]{2}{*}{ Ostellato (Italy) } & Pandas & $28 \mathrm{Apr}$ & $28 \mathrm{Apr}$ & 9 & 9.3 \\
\hline & Centauro & 1 May & 2 May & 10 & 9.8 \\
\hline \multirow[t]{3}{*}{ Stuard (Italy) } & Pandas & $6 \mathrm{May}$ & 4 May & 9 & 9.3 \\
\hline & Costantino & 9 May & $8 \mathrm{May}$ & 9 & 9.7 \\
\hline & Salmone & $11 \mathrm{May}$ & 11 May & 10 & 10.2 \\
\hline
\end{tabular}

applied agriculture (de Wit 1978). In particular, a model that simulates and predicts the development of wheat in the field can be of great value for agronomy (Kirby 1988) and of help to breeders, as well as to researchers, studying the impact of climate changes upon agriculture (Miglietta \& Porter 1991).

The optimal time for applying fertilizers and hormone-based herbicides is more closely related to apical 


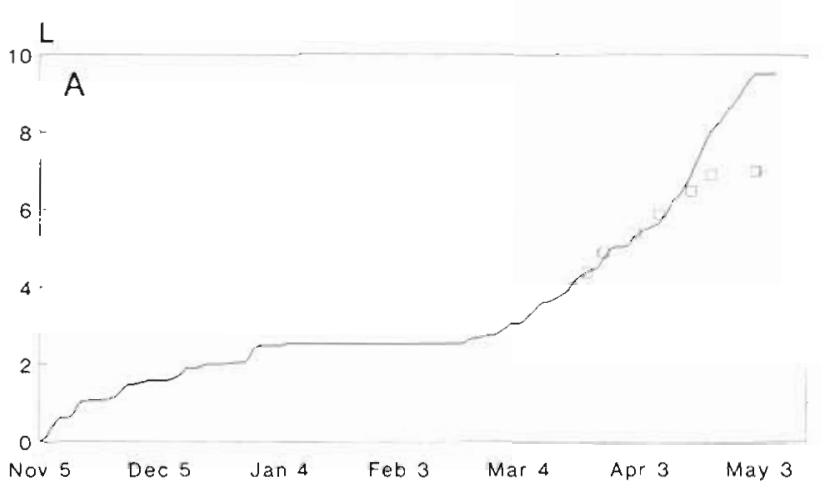

$10^{\mathrm{L}}$

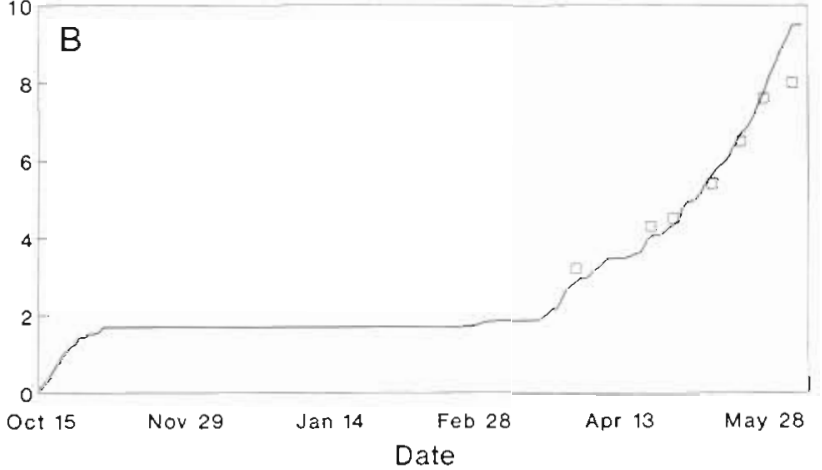

Fig. 7. (-) Simulated and (D) observed number of emerged main stem leaves ( $\mathrm{L}$ ) of the variety 'Colt' at (A) Manhattan. Kansas, in the 1985-86 season and (B) Mandan, North Dakota, in the $1984-85$ season

and leaf development than to calendar dates. The model discussed here makes it possible to predict the time of floral induction with sufficient accuracy and to simulate the appearance of subsequent main stem leaves.

Screening varieties for earliness of maturity and adaptation to a given environment requires a knowledge of different genotypes photoperiodic and vernalisation responses. The final number of leaves formed in the field by different varieties is a useful selection criterion; thus, a model that predicts the final number of main stem leaves of crops grown at any latitude and in any climate can be successfully applied in breeding programs.

The effect of expected climatic changes related to increased atmospheric $\mathrm{CO}_{2}$ can also be studied using this model. Model runs can be performed both to assess the direct effect of increasing temperatures upon wheat development and to identify the ideotype variety which will be better adapted to such changes. However, further research is needed to create a complete ontomorphogenetic model for wheat. Such a model, in fact, should be able to estimate the effects of variety, climate, mineral nutrition and water stress on the final size of main stem and tiller leaves and on the development of leaf cover under field conditions.
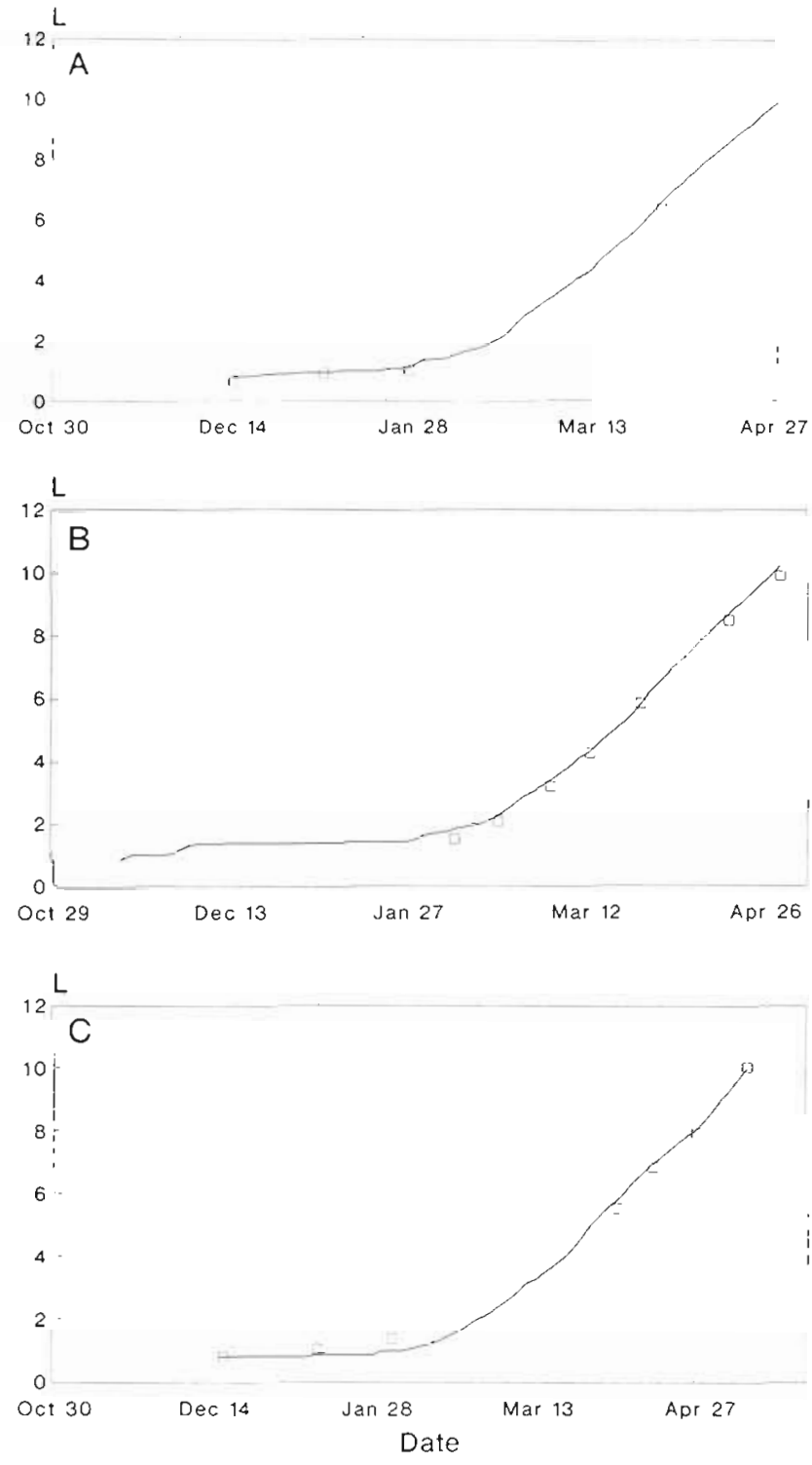

Fig. 8. (-) Simulated and (C) observed number of emerged main stem leaves (L) of the variety 'Colt' at (A.) Martorano 5,

(B) Stuard and (C) Ostellato farms in Italy, in 1988-89

Acknowledgements. The author thanks C. T de Wit for discussion, R. Reginato for providing data diskettes of the experiments conducted in the USA, L. Bacchi-Lazzeri, C. Piazza, and A. Zani for their coordination of the field experiments, and in particular, G. Maracchi, who made this work possible.

\section{LITERATURE CITED}

Allison, J. C. S., Daynard, T. B. (1976). Effect of photoperiod on development and number of spikelets of a temperate and some low latitude wheats. Ann. appl. Biol. 83: 93-102

Bauer, A., Garcia, R., Kanemasu, E. T., Blad, B. L., Hatfield, J. L., Major, D. J., Reginato, R. J. (1988). Effect of latitude on phenology of Colt winter depth. Agric. For. Meteorol. $44(2): 131-140$ 
Bauer, A., Smika, D., Balck, A. (1983). Correlation of five wheat growth scales used in the Great Plains. Adv. Agric. Tech., North Central 7, USDA-ARS, Peozia, IL

Bindi, M., Maracchi, G., Miglietta, F. (1989). WIRS, una database relazionale contenente informazioni sulla coltura del frumento in Italia. Quaderni Ce.S.I.A. No. XXI, Florence

CERAS (Consorzio Emiliano-Romagnolo Aziende Sperimentali) (1960-1989). Risultati delle prove sperimetnali e dimostrative: cereali. Nuova Tipografia S. Francesco, Bologna

Davidson, H. r. Campbell, C. A. (1983). The effect of temperature, moisture and nitrogen on the rate of development of spring wheat as measured by degree days. Can. J. Plant Sci. 63: 833-846

de Wit, C. T (1978). Simulation of assimilation, respiration and transpiration of crops. Simulation monographs. Pudoc, Wageningen

Frank, A. B., Bauer, A. (1982). Effect of temperature and fertilizer $\mathrm{N}$ on apex development in spring wheat. Agron. J. $74: 504-509$

Gallagher, J. N., Biscoe, P. V., Wallace, J. S. (1979). Field studies of cereal leaf growth. IV. Winter wheat leaf extension in relation to temperature and lef water status. J. cxp. Bot. 30: $657-668$

Kirby, E. J. M. (1988). Significant stages in cereal development. In: Miglietta, F. (ed.) Models in agriculture and forest research. IPRA-CNR, Rome, p. 79-95

Holmes, D. P. (1972). Inflorescence development of semidwarf and standard height wheat cultivars in different photoperiod and nitrogen treatments. Can. J. Bot. 51. 941-955

Hubbard, K. G., Blad, B. L., Verma, S. B., Bauer, A., Hatfield, J. L., Kanemasu, E. T., Major, D. J., Reginato, R. J. (1988). Monitoring the weather at five winter wheat experimental field sites. Agric. For Meteorol. 44(2): 117-130

Levy, J., Peterson, M. (1972). The effect of daylength on primordia production of the wheat apex. Aust. J. biol. Sci. 25: $649-656$

Editor: G. Esser
Major, D. J., Blad, B. L., Bauer, A., Hatfield, J. L., Hubbard, K. G. Kanemasu, E. T., Reginato, R. J. (1988a). Winter wheat grain yield response to water and nitrogen on the North American Great Plains. Agric. For. Meteorol. 44(2): $141-150$

Major, D. J., Blad, B. L., Bauer, A., Hatfield, J. L., Hubbard, K. G., Kanemasu, E. T., Reginato, R. J. (1988b). Seasonal patterns of winter wheat phytomass as affected by water and nitrogen on the North American Great Plains. Agric For. Meteorol. 44(2): 151-158

Masle-Meynard, J., Sebillotte, M. (1981). Etude de l'eterogeneité d'un peuplement de blé d'hiver. I. Notion de structure du peuplement. Agronomie 1(3): 207-216

Miglietta, F. (1989). The effect of photoperiod and temperature on leaf initiation rates in wheat (Triticum spp.). Field Crop Res. 21(2): 121-131

Miglietta, F. (1991a). Simulation of wheat ontogenesis. I. Appearance of main stem leaves in the field. Clim. Res. 1: $145-150$

Miglietta, F. (1991b). Simulation of wheat ontogenesis. II. Predicting dates of ear emergence and main stem final leaf number. Clim. Res. 1: 151-160

Miglietta, F., Porter, J. R. (1991). The effect of climate change on agriculture: analysis and modelling. J. exp. Bot. (in press)

Pirasteh, B., Welsh, J. R. (1980). Effect of temperature on the heading date of wheat under a lengthening photoperiod Crop Sci. 20: 453-456

Rahman, M. S., Wilson, J. M. (1977). Determination of spikelet number in wheat. 1 . The effect of varying photoperiod on ear development. Aust. J. agric. Res. 28: 565-574

Reginato, R. J., Hatfield, J. L., Bauer, A., Hubbard, K. G., Blad B. L., Verma, S. B., Kanemasu, E. T., Major, D. J. (1988) Winter wheat response to water and nitrogen in the North America Great Plains. Agric. For. Meteorol. 44(2): 105-116

Syme, J. R. (1974). Leaf appearance rate and associated characters in some Mexican and Australian wheats. Aust. J. agric. Res. 25: 1-7

Manuscript first received: January 17, 1991

Revised version accepted: June 20,1991 